\title{
COMPERASION STUDY ON LOW PRESSURE EMTF NOZZLES BASED ON DROPLETS SIZE CHARACTERISTICS
}

\author{
Sehsah, E.M.E* and H.Ganzelmeier**
}

\section{ABSTRACT}

The current study carried out in the Federal Biological Research Centre for Agriculture and Forestry (JKI) Braunschweig, Germany. The goals of this research were to measure the droplet size for the developing external mixing twin fluid nozzles (EMTF) that will target and spray the pesticide, especially biological and herbicides pesticides. As well as investigating to find the optimum combinations of the EMTF nozzles from the available nozzles that applied in the field of agriculture. Also the reduction of the water volume rate is an important aspect in the current research to reduce application costs. The tongue nozzle (Lechler FT5-608) for the air and the eight different nozzles from Lechler and Tee Jet for the liquid nozzle were selected to obtain the combinations of EMTF nozzles. Oxford lasers "VisiSizer" system PDIA was used to test and measured the droplets size from different EMTF nozzles.

The two levels of air pressures 150 (1.5 bar) and $200 \mathrm{kPa}(2 \mathrm{bar})$ at liquid pressures 30 (0.3 bar) and $60 \mathrm{kPa}(0.6 \mathrm{bar})$ and two colangling (injection angles) $60^{\circ}$ and $45^{\circ}$ were tried to study their effect on droplets size, as well as to find the optimum EMTF nozzle configuration. It was found that the external mixing twin fluid could be producing the different droplet spectrum from medium to very fine droplet at low liquid pressure. The external mixing twin fluid nozzle combination N1 (TT11003+ Lechler FT 5 - 608) produce the medium spectrum compared to the N2, N2, N3, N4, N5, N6, N7 and N8 EMTF nozzles combinations. The spray characteristics droplets size Dv0.1, Dv0.5 and Dv0.9 for N1 EMTF nozzle are $95.2 \mu \mathrm{m}, 226.6 \mu \mathrm{m}$, and $486.3 \mu \mathrm{m}$ at $150 \mathrm{kPa}$ (1.5 bar) air pressures; and $77.2 \mu \mathrm{m}, 171.2 \mu \mathrm{m}$, and $450 \mu \mathrm{m}$ at $200 \mathrm{kPa}(2 \mathrm{bar})$ air pressures respectively.

*Dr. Sehsah, El-Sayed Mahmoud El-Beily, Dept. of Agric. Eng. Faculty of Agricultural, Kafr El-Sheikh University, 33516-kafr El-Sheikh, Egypt E-Mail sehsah_2000@yahoo.de

${ }^{\star * *}$ Prof. Dr. Heinz Ganzelmeier, Federal Biological Research Centre for Agriculture and Forestry Braunschweig, Application Techniques Division, Messeweg 11/12,D-38104 Braunschweig, Germany E-mail: heinz.ganzelmeier@jki.bund.de. 
On the other hand, the N5 (Lechler LU 120-015 POM +Lechler FT 5 608) nozzle produce the fine spectrum at the above air and liquid pressure conditions. As well as the result indicated that the external mixing twin fluid could be reducing the water volume rate. The increase of liquid pressure tends to decrease of the droplet size spectra. By changing the injection angle may able to produce the finest droplet without any increasing of the applied costs. Also it is able to use the widely available agricultural nozzles to make the external mixing twin fluid which are working at low spray pressure.

Key words: Low pressure, Droplet size, Nozzles

\section{INTRODUCTION}

he external mixing twin fluid principle is still in a theoretical
stage and requires development toward practical application. The
most important factor for applicable the living organisms is the nozzles size in External mixing twin fluid and the impact area of the turbo drop liquid atomizer. The challenge is to optimize the hydraulic system of the sprayer to avoid any additional shear stress to the living organisms (Sehsah, 2005 and Sehsah and Kleisinger 2007).

Hydraulic nozzles produce sprays with a range of droplet sizes and velocities (Lefebvre, 1989). These variations can affect the efficient application of agricultural sprays. The safe and efficient application of pesticides requires, among other things, the definition of an appropriate droplet size spectrum. A review of interests affecting the selection of parameters for spraying operations was given by Matthews (1979) and Hewitt (1997). The ideal spectrum will maximize spray efficiency for depositing and transferring a lethal dose to the target, while minimizing off-target losses such as spray drift and user exposure (Elliot and Wilson, 1983a). Take et al. (1996) showed that the droplet size spectrum of a spray application and the factors that affect this spectrum, are the most important variables affecting spray deposition levels downwind of the application area. Considering the importance of droplet size upon spray performance, drift minimization and the given range of nozzles available for spray application, it is logical that sprays should be classified according to droplet size. Systems have been developed by the British Crop Protection Council (BCPC) and American Society of Agricultural 
Engineers (ASAE) for classifying agricultural sprays by droplet size. Sprays produced by the interaction of air and liquid are known to produce droplets with air inclusions (Rutherford et al., 1989). It has been recognized that these inclusions could cause difficulties with techniques that rely on diffraction and refraction (Tuck et al., 1997). This could limit the measurement systems that can reliably be used for these nozzle designs to those based upon imaging. The major atomizer categories have been defined according to the primary energy sources responsible for spray development (ASAE, 2003). For these devices, theory predicts and experiments confirm that mean droplet diameter size is roughly proportional to the square root of initial liquid jet diameter or sheet thickness.

Reduction of pesticides application is possible only when there is a real economic need, switching to new, more effective technologies, improving pesticides spraying equipment and technologies, changing old preparative to new ones more effectives that are to be used in smaller doses. The current research study investigates the External mixing twin fluid nozzles as a suitable sprayer technology for Bio-pesticides and herbicides. The main objectives of the current research part are:

-To measure the spray spectrum from the low pressure external mixing twin fluid nozzles which may be reduce the water volume rate and application costs.

-To obtain the optimum external mixing twin fluid nozzles combinations from different available agricultural nozzles.

\section{MATERIALS AND METHODS}

\section{PDIA Instrumentation and Technique}

The PDIA system was used in the laboratory of the Federal Biological Research Centre for Agriculture and Forestry (JKI) Braunschweig, Germany.

Oxford lasers "VisiSizer" system provides an automated PDIA method to obtain average diameter information from a set of images of a spray. The system comprises of a pulsed light source, camera, timing and PC. The PDIA technique uses backlit-imaging arrangement, where the output from the laser is expanded through a diffuser to break up the coherence of the laser light. A CCD digital camera captures images at $30 \mathrm{~Hz}$, with 
image resolution of $1008 \times 1008$ pixels and data rates up to 7500 droplets per second. The sized droplets are numbered and the $\mathrm{X}$ indicates a focus rejection. Images of droplets touching the image border have been automatically rejected along with those that occupy fewer than 10 pixels. The pulsed laser freezes the motion of the droplet (maximum allowed movement is $1.0 \%$ of the particle diameter, during the laser pulse), and provides illumination for the images. A threshold grey-level is set on the images, and the automated algorithm then effectively scans across the image pixel by pixel and based on the set threshold level, determines which pixels correspond to the background and which correspond to the droplet. In order that the droplets are accurately sized, the intensity gradient at the edge of the droplet is measured to determine the degree of focus.

\section{Measuring Protocol}

Before any PDIA Leaser measurements, the flow rate of each nozzle combinations are tested at two liquid nozzles by the standard cylinder and stopwatch. For the PDIA measurements in these tests, the different combinations nozzles were selected. The combination of the EMTF nozzle were selected and illustrated in Table 1. The measured droplet spectra as the nozzle discharge was scanning through the laser sampling volume located $50 \mathrm{~cm}$ below the plane of the nozzle (Pearson et al., 1993). Each scan yielded data for at least 10000 droplets as recommended by Adams et al (1990). All measurements were made spraying water at a temperature of approximately $20^{\circ} \mathrm{C}$. Environmental conditions were kept constant at a temperature of $20^{\circ} \mathrm{C}$ and a relative humidity between 70 and $80 \%$. To enable the whole of sprays to be sampled, the nozzle was mounted on the transporter. A different scan trajectory (fig.1) was programmed depending on the type of nozzle combinations. All measurements were carried out through the long axis of the spray could at a constant scan speed. The $\mathrm{Y}$ and $\mathrm{X}$ values were controlled at $250 \mathrm{~mm}$ and $800 \mathrm{~mm}$ respectively. In the current research, the droplets spectra are measured in different optical path lengths to scan the all trajectory for the different combinations of the EMTF nozzles as shown in figure 2 . 


\section{External Mixing Twin Fluid nozzles (EMTF)}

The EMTF nozzle was developed in Hohenheim University, Germany as the part of the applicable technique for the biological material (Sehsah, 2005). Figure 3 indicate the functional diagram of an external mixing twin fluid (EMTF) nozzle and the contact angle between air jet and liquid sheet. The principle of the external mixing twin fluid nozzle is the injection of a liquid sheet into air sheet, both produced by tongue nozzles. At the merging line, the high-speed air stream will disintegrate the liquid sheet and produce droplets. With External mixing twin fluid nozzles, the liquid sheet or jet exposed to the atomizing air has little initial momentum and the droplets formed in atomization are entirely dependent on the kinetic energy of the atomizing air to transport them away from the nozzle into the target.

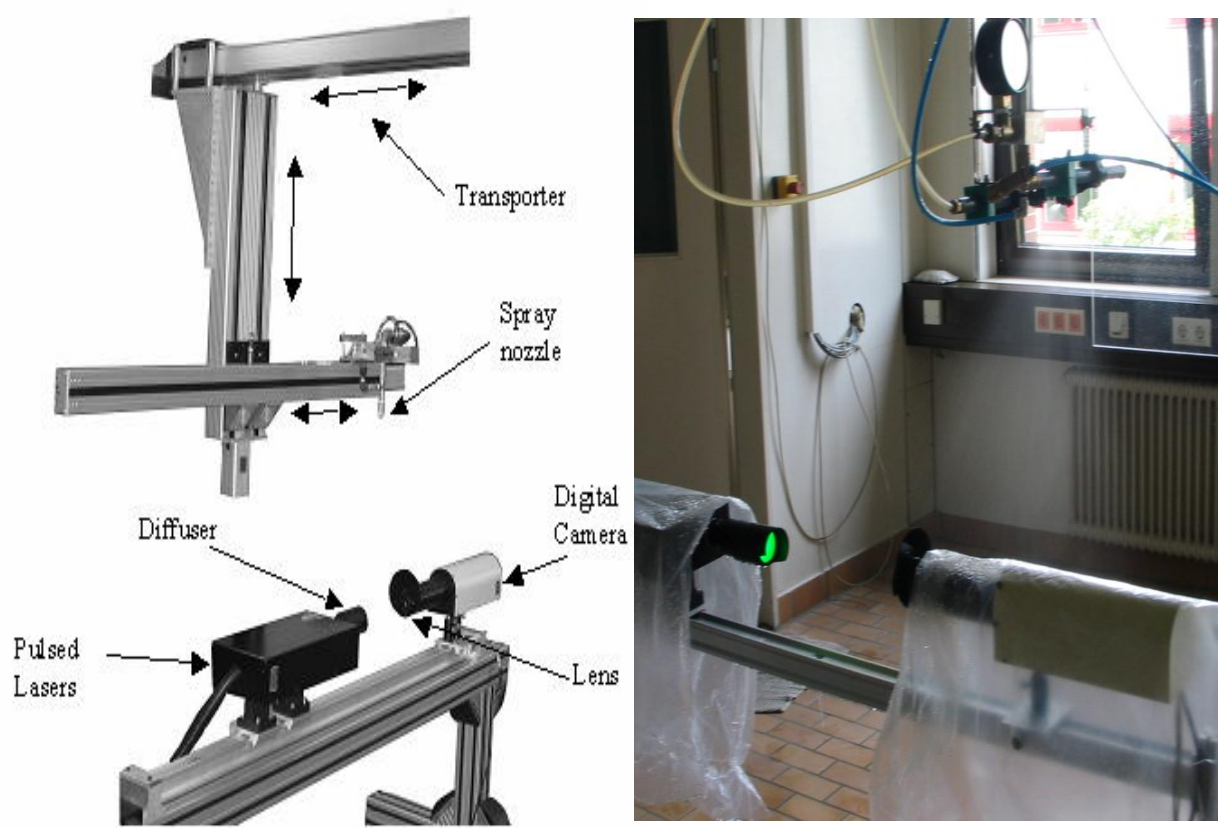

Fig. 1: Layout of main components of the PDIA Oxford Lasers VisiSizer system.

The injection angle between the liquid sheet and the air sheet can be calculated by the well known trigonometric function:

$$
\tan \phi=\left[\frac{\mathrm{Y}^{\prime \prime}}{\mathrm{X}^{\prime \prime}}\right]
$$


Where:

$\mathrm{Y}^{\prime \prime}=$ the vertical distance of liquid nozzle position $\quad[\mathrm{mm}]$

$\mathrm{X}^{\prime \prime}=$ the horizontal distance of liquid nozzle position $\quad[\mathrm{mm}]$

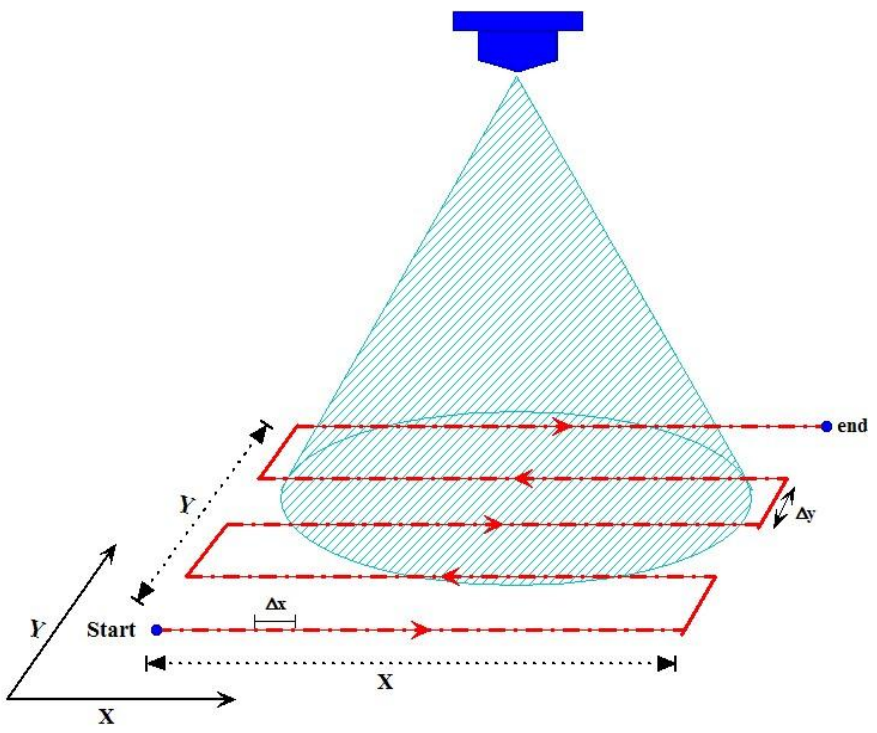

Fig. 2: Measuring of the droplets spectrum by scanning through the trajectory.

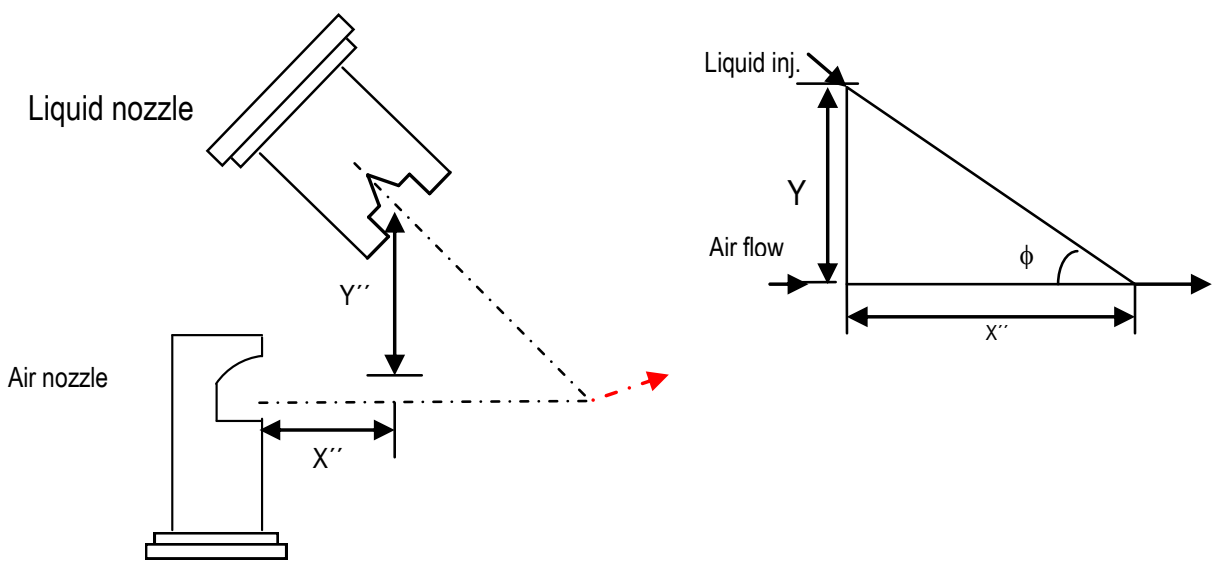

Fig. 3: Functional diagram of an external mixing twin fluid (EMTF) nozzle and the contact angle between air jet and liquid sheet $\phi$ contact angle between air and liquid boundary, $\mathrm{X}^{\prime}$ horizontal distance between the air and liquid nozzles, $\mathrm{Y}^{\prime \prime}$ Vertical distance of liquid nozzle position and $\mathrm{X}^{\prime \prime}$ Horizontal distance of liquid nozzle position 
The flow rate from the different EMTF nozzles was measured and listed in table 2. The hypotheses of the data analysis were to assume that the droplets spectrum is affected by a number of factors and situations. The factors are the combination of EMTF nozzles and injection angle. These include the liquid pressure, as well as pressure of air which used to atomize the liquid spray by FT 5 nozzle of air.

\section{Data Interpretation}

Test results conform that the main factor affecting droplets size are combinations of the external mixing twin fluid (EMTF) nozzles, air pressure liquid pressure and injection angle. A higher air pressure and liquid pressure, for different EMTF nozzles results suggest that droplets size were fine. Higher air and liquid pressure caused more shear a cross the atomizer, which can produce finer sprays, although the relative liquid to air velocity is an important consideration. By itself, Injection angle did not have a large effect on the droplets size. On the other hand, the injection angle was significant effect when it interacted with the other factors, nozzle combinations air and liquid pressure.

The JKI recommendation for classification of the droplets size spectrum was used to classify the different selected external mixing twin fluid nozzles in the current research. Droplet size classes are shown in the following tables to assist in choosing an appropriate spray tip table 3.

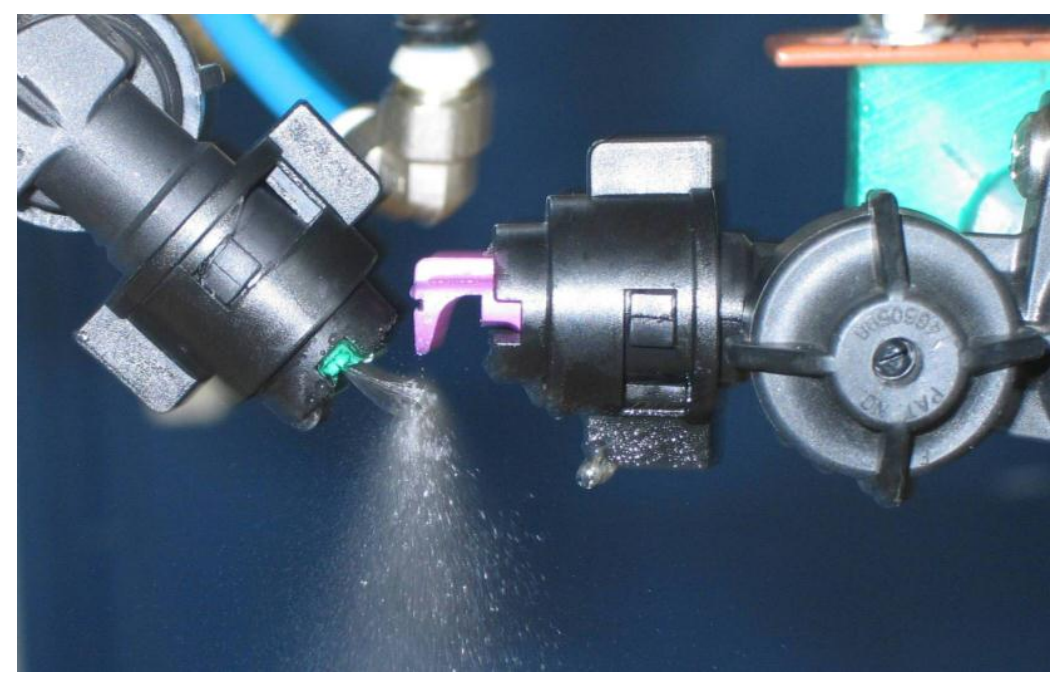

Fig. 4: Illustrates the combination of a tongue nozzle (Lechler FT5.0) for the air and a LU 110-015 for the liquid. 
Table 1. The combinations of the external mixing twin fluid (EMTF) nozzles.

\begin{tabular}{ccl}
\hline \multirow{2}{*}{ EMTF } & \multicolumn{2}{c}{ Nozzles } \\
\cline { 2 - 3 } Nozzles & \multicolumn{1}{c}{ Air nozzles } & \multicolumn{1}{c}{ Liquid nozzles } \\
\hline N 1 & Lechler FT 5 - 608 & Tee Jet TT11003 POM \\
N 2 & Lechler FT 5 - 608 & Lechler AD90-03 C \\
N 3 & Lechler FT 5 - 608 & Lechler AD120-03 POM \\
N 4 & Lechler FT 5 - 608 & Lechler LU90-04 POM \\
N 5 & Lechler FT 5 - 608 & Lechler LU 120-015 POM \\
N 6 & Lechler FT 5 - 608 & Lechler LU 120-03 POM \\
N 7 & Lechler FT 5 - 608 & Tee Jet XR11003 VP \\
N 8 & Lechler FT 5 - 608 & Tee Jet XR8004 VK \\
\hline
\end{tabular}

Table 2. Measuring flow-rate for different EMTF Nozzles combinations, 1/min.

\begin{tabular}{lcc}
\hline & \multicolumn{2}{c}{ Flow-rate, $1 /$ min } \\
\cline { 2 - 3 } \multicolumn{1}{c}{ Nozzles of liquid } & $\begin{array}{c}\text { Liquid Pressure, } \\
30 \mathrm{kPa}\end{array}$ & $\begin{array}{c}\text { Liquid Pressure, } \\
60 \mathrm{kPa}\end{array}$ \\
\hline Tee Jet TT11003 & 0.39 & 0.64 \\
Lechler AD90-03 C & 0.35 & 0.50 \\
Lechler AD120-03 POM & 0.40 & 0.56 \\
Lechler LU 90-04 POM & 0.40 & 0.54 \\
Lechler LU 120-015 POM & 0.20 & 0.31 \\
Lechler LU 120-03 POM & 0.48 & 0.69 \\
Tee Jet XR11003 VP & 0.43 & 0.54 \\
Tee Jet XR8004 VK & 0.44 & 0.71 \\
\hline
\end{tabular}

Table 3. Classification of the droplet size by the recommendation of JKI.

\begin{tabular}{l|c}
\hline \multicolumn{1}{c|}{ Droplet Spectrum } & Droplet size, $\mu \mathrm{m}$ \\
\hline Very fine (VF) & $<130$ \\
Fine (F) & $130-224$ \\
Medium (M) & $224-283$ \\
Coarse (C) & $283-435$ \\
Very coarse (VC) & $>435$ \\
\hline
\end{tabular}

JKI: Julius Kühn-Institut ; The federal research centers of the German Federal Ministry of Food, Agriculture and Consumer Protection, AT division, Braunschweig, Germany. 


\section{RESULTS AND DISCUSSIONS}

The statistical software package used in the analysis was JMP, version 8 (SAS Institute, Inc., Cary, N.C). The approach was the factorial analysis: the combination of the EMTF nozzles was the main factor affecting on droplets size. The two levels of air pressures 150 (1.5 bar) and $200 \mathrm{kPa}(2$ bar) at liquid pressures 30 (0.3 bar) and $60 \mathrm{kPa}(0.6 \mathrm{bar})$ and two injection angles $60^{\circ}$ and $45^{\circ}$ were tried to study their effect on droplets size, as well as to find the optimal nozzle configuration. An important point to select a spray nozzle which produces a droplet size in one of the three categories is that one nozzle can produce different droplet size classifications at different pressures. A nozzle might produce medium droplets at low pressure, while producing fine droplets as pressure is increased. Table 4 indicates the classification of the references nozzles by using the JKI recommendation at low (1 bar) and high liquid (6 bar) pressures. The reference nozzles are used to define the boundaries of the six spray categories. This classification is based on the comparison of the droplet size spectrum $\left(\mathrm{D}_{\mathrm{v} 0.1}, \mathrm{D}_{\mathrm{v} 0.5}\right.$ and $\left.\mathrm{D}_{\mathrm{v} 0.9}\right)$ produced by a nozzles at a given pressure with these reference spectra as shown in table 4 .

\section{Effect of the Nozzles Combinations in EMTF}

The interaction of the effect of the nozzles combinations in EMTF nozzles, injection angle air and liquid pressures on $\mathrm{D}_{\mathrm{v} 0.1}, \mathrm{D}_{\mathrm{v} 0.5}$ and $\mathrm{D}_{\mathrm{v} 0.9}$ illustrated in table 5, 6, 7 and 8. It is clear that the external mixing twin fluid nozzles may be producing the different droplet spectrum from medium to very fine droplet at low liquid pressure. It is observed that the combination of the external mixing twin fluid nozzles gave the highly effect on the droplet spectrum compared to the factors injection angle air and liquid pressures.

It may therefore be concluded that the droplets size are more strongly dependant on the combinations of nozzles in the EMTF nozzles, which is highly significant in data. The external mixing twin fluid nozzle N1 (TT11003+ Lechler FT 5 - 608) produce the medium spectrum compared to the other EMTF nozzles combinations at $150 \mathrm{kPa}$ (1.5 bar) air pressure and low liquid pressure $30 \mathrm{kPa}(0.3 \mathrm{bar})$. On the other hand, the N5 (Lechler LU 120-015 POM +Lechler FT 5 - 608) nozzle produce the fine spectrum at the above air and liquid pressure conditions. The N1 EMTF 
nozzle droplets size $D_{v 0.1}, D_{v 0.5}$ and $D_{v 0.9}$ are $95.2 \mu \mathrm{m}, 226.6 \mu \mathrm{m}$, and $486.3 \mu \mathrm{m}$ at $150 \mathrm{kPa}(1.5 \mathrm{bar})$ air pressures; and $77.2 \mu \mathrm{m}, 171.2 \mu \mathrm{m}$, and $450 \mu \mathrm{m}$ at $200 \mathrm{kPa}$ (2 bar) air pressures respectively. It is also observed that both N1(TT11003+ Lechler FT 5 - 608) and N5 (Lechler LU 120015 POM +Lechler FT 5 - 608) EMTF nozzles are worked at low flow rate $0.641 \mathrm{~min}^{-1}$ and $0.311 \mathrm{~min}^{-1}$ at $60 \mathrm{kPa}(0.6 \mathrm{bar})$ spray or liquid pressure respectively. It's clearly that, the external mixing twin fluid able to reduce the water volume application when it's used to apply the living organisms and the other pesticides spatially the herbicides.

It was also found that the EMTF nozzles N4, N5 and N6 produce the very fine droplets size compared to the $\mathrm{N} 1, \mathrm{~N} 2, \mathrm{~N} 3, \mathrm{~N} 7$ and $\mathrm{N} 8$ at same operating conditions. The EMTF nozzles could be gave the same droplet spectrum at low liquid pressure compared to the references nozzles or standard flat fan nozzles which should be operating at highest liquid pressure. It means also, the EMTF nozzles could be reduce the costs of the spray application, and further more reduce the water volume.

Table 4. The droplets size spectrum of the reference nozzles in the external mixing twin fluid nozzles.

\begin{tabular}{ccccccccccc}
\hline & \multicolumn{8}{c}{ droplets spectrum of reference nozzles at lower and higher pressure } \\
\cline { 2 - 11 } Nozzle & $\begin{array}{c}\text { Pressure, } \\
\mathrm{kPa}\end{array}$ & $\mathrm{D}_{\mathrm{v} 0.1}$ & $\mathrm{D}_{\mathrm{v} 0.5}$ & $\mathrm{D}_{\mathrm{v} 0.9}$ & $\begin{array}{c}\text { Droplet } \\
\text { Spectrum }\end{array}$ & $\begin{array}{c}\text { Pressure, } \\
\mathrm{kPa}\end{array}$ & $\mathrm{D}_{\mathrm{v} 0.1}$ & $\mathrm{D}_{\mathrm{v} 0.5}$ & $\mathrm{D}_{\mathrm{v} 0.9}$ & $\begin{array}{c}\text { Droplet } \\
\text { Spectrum }\end{array}$ \\
\hline $\mathrm{N} 1$ & 100 & 240.0 & 440.0 & 654.0 & $\mathrm{VC}$ & 500 & 126.0 & 256.0 & 453.0 & $\mathrm{M}$ \\
$\mathrm{N} 2$ & 200 & 138.5 & 301.0 & 587.2 & $\mathrm{C}$ & 600 & 117.0 & 237.0 & 413.0 & $\mathrm{M}$ \\
$\mathrm{N} 3$ & 150 & 137.5 & 296.9 & 564.7 & $\mathrm{C}$ & 600 & 102.7 & 202.7 & 391.6 & $\mathrm{~F}$ \\
$\mathrm{~N} 4$ & 150 & 134.1 & 287.9 & 423.0 & $\mathrm{C}$ & 600 & 102.0 & 187.0 & 289.3 & $\mathrm{~F}$ \\
$\mathrm{~N} 5$ & 150 & 113.7 & 223.0 & 311.0 & $\mathrm{~F}$ & 600 & 105.1 & 169.9 & 243.0 & $\mathrm{~F}$ \\
$\mathrm{~N} 6$ & 150 & 121.0 & 238.0 & 354.0 & $\mathrm{M}$ & 600 & 86.0 & 174.0 & 277.0 & $\mathrm{~F}$ \\
$\mathrm{~N} 7$ & 150 & 135.0 & 265.0 & 405.0 & $\mathrm{M}$ & 600 & 92.0 & 188.0 & 298.0 & $\mathrm{~F}$ \\
$\mathrm{~N} 8$ & 150 & 192.0 & 382.0 & 570.0 & $\mathrm{C}$ & 600 & 116.0 & 233.0 & 405.0 & $\mathrm{M}$ \\
\hline
\end{tabular}

\section{Effect of spray liquid pressure}

In table 6, the air pressure was none highly significant effect on the spray droplet spectra for all combinations of nozzles N1, N2, N3, N4, N5, N6, $\mathrm{N} 7$ and N8. In figure 5, the study of the interaction of the effect of the air 
and low liquid pressure was significant effect only on the $\mathrm{D}_{\mathrm{v} 0.5}$ and highly effect on the $D_{v 0.9}$. On the other hand, it was none significant effect on the $D_{\mathrm{v} 0.1}$. The increase of liquid pressure tends to decrease of the droplet size spectra. As well as, the statistical analysis indicated that, the interaction between the low liquid pressures with injection angle was none significant on the spray spectra. It is clearly that the liquid pressure is one importance factor affecting on the spray spectrum. The spray droplet characteristics $\mathrm{D}_{\mathrm{v} 0.1}, \mathrm{D}_{\mathrm{v} 0.5}$ and $\mathrm{D}_{\mathrm{v} 0.9}$ for N1 (Lechler FT 5-608 \& TT110-03) nozzle were $89.1 \mu \mathrm{m}, 213.3 \mu \mathrm{m}$ and $539.5 \mu \mathrm{m}$ at $30 \mathrm{kPa}$ liquid pressure respectively. As well as, the spray droplet characteristics $\mathrm{D}_{\mathrm{v} 0.1}, \mathrm{D}_{\mathrm{v} 0.5}$ and $\mathrm{D}_{\mathrm{v} 0.9}$ for N1 (Lechler FT 5-608 \& TT110-03) nozzle were $83.3 \mu \mathrm{m}, 184.4 \mu \mathrm{m}$ and $397 \mu \mathrm{m}$ at $60 \mathrm{kPa}$ liquid pressure respectively. In addition to, the spray droplet characteristics $D_{\mathrm{v} 0.1}, D_{\mathrm{v} 0.5}$ and $\mathrm{D}_{\mathrm{v} 0.9}$ for N5 (Lechler FT 5-608 \& LU120-015) nozzle were $47.7 \mu \mathrm{m}, 109.7 \mu \mathrm{m}$ and $200.2 \mu \mathrm{m}$ at $30 \mathrm{kPa}$ liquid pressure respectively. As well as, the spray droplet characteristics $\mathrm{D}_{\mathrm{v} 0.1}, \mathrm{D}_{\mathrm{v} 0.5}$ and $\mathrm{D}_{\mathrm{v} 0.9}$ for N5 (Lechler FT 5$608 \&$ LU1120-015) nozzle were $44.5 \mu \mathrm{m}, 100.9 \mu \mathrm{m}$ and $180.3 \mu \mathrm{m}$ at $60 \mathrm{kPa}$ liquid pressure respectively .

Table 5. The interaction of the effect of the EMTF nozzle types and air pressure on the droplets size spectrum.

\begin{tabular}{ccccccccc}
\hline & \multicolumn{9}{c}{ Air Pressure } & \multirow{2}{*}{ Droplet Spectrum } \\
\cline { 2 - 8 } Nozzles & \multicolumn{3}{c}{$150 \mathrm{kPa} a$} & \multicolumn{3}{c}{$200 \mathrm{kPa}$} & & \\
\cline { 2 - 8 } & $\mathrm{D}_{\mathrm{v} 0.1}$ & $\mathrm{D}_{\mathrm{v} 0.5}$ & $\mathrm{D}_{\mathrm{v} 0.9}$ & $\mathrm{D}_{\mathrm{v} 0.1}$ & $\mathrm{D}_{\mathrm{v} 0.5}$ & $\mathrm{D}_{\mathrm{v} 0.9}$ & $150 \mathrm{kPa}$ & $200 \mathrm{kPa}$ \\
\hline N1 & $\mathbf{9 5 . 2}$ & $\mathbf{2 2 6 . 6}$ & $\mathbf{4 8 6 . 3}$ & $\mathbf{7 7 . 2}$ & $\mathbf{1 7 1 . 2}$ & $\mathbf{4 5 0 . 4}$ & medium & Fine \\
N2 & 56.2 & 134.4 & 274.5 & 46.7 & 107.0 & 206.7 & Fine & Very fine \\
N3 & 63.1 & 153.1 & 291.9 & 54.7 & 132.1 & 241.1 & Fine & Fine \\
N4 & 55.2 & 124.7 & 251.4 & 48.9 & 108.2 & 202.9 & Very fine & Very fine \\
N5 & $\mathbf{4 9 . 4}$ & $\mathbf{1 1 2 . 5}$ & $\mathbf{1 9 6 . 2}$ & $\mathbf{4 2 . 8}$ & $\mathbf{9 8 . 0}$ & $\mathbf{1 8 4 . 3}$ & Very fine & Very fine \\
N6 & 51.5 & 115.1 & 218.0 & 50.8 & 112.3 & 199.5 & Very fine & Very fine \\
N7 & 69.0 & 145.9 & 277.7 & 63.1 & 138.0 & 261.1 & Fine & Fine \\
N8 & 66.4 & 146.3 & 281.6 & 60.8 & 137.1 & 242.1 & Fine & Fine \\
\hline
\end{tabular}


Table 6. The interaction between types of EMTF nozzles and air pressure, and their effects on the droplets size spectrum.

\begin{tabular}{ccccccccc}
\hline & \multicolumn{9}{c}{ Liquid Pressure } & \multirow{2}{*}{ Droplet Spectrum } \\
\cline { 2 - 8 } Nozzles & \multicolumn{3}{c}{$30 \mathrm{kPa}$} & \multicolumn{3}{c}{$60 \mathrm{kPa}$} & & \\
\cline { 2 - 8 } & $\mathrm{D}_{\mathrm{v} 0.1}$ & $\mathrm{D}_{\mathrm{v} 0.5}$ & $\mathrm{D}_{\mathrm{v} 0.9}$ & $\mathrm{D}_{\mathrm{v} 0.1}$ & $\mathrm{D}_{\mathrm{v} 0.5}$ & $\mathrm{D}_{\mathrm{v} 0.9}$ & $30 \mathrm{kPa}$ & $60 \mathrm{kPa}$ \\
\hline N1 & $\mathbf{8 9 . 1}$ & $\mathbf{2 1 3 . 3}$ & $\mathbf{5 3 9 . 8}$ & $\mathbf{8 3 . 3}$ & $\mathbf{1 8 4 . 4}$ & $\mathbf{3 9 7 . 0}$ & Fine & Fine \\
N2 & 52.9 & 125.0 & 257.9 & 50.0 & 116.4 & 223.4 & Very fine & Very fine \\
N3 & 62.1 & 155.1 & 313.4 & 55.7 & 130.1 & 219.7 & Fine & Fine \\
N4 & 52.8 & 121.1 & 245.3 & 51.3 & 111.9 & 209.0 & Very fine & Very fine \\
N5 & $\mathbf{4 7 . 7}$ & $\mathbf{1 0 9 . 7}$ & $\mathbf{2 0 0 . 2}$ & $\mathbf{4 4 . 5}$ & $\mathbf{1 0 0 . 9}$ & $\mathbf{1 8 0 . 3}$ & Very fine & Very fine \\
N6 & 52.8 & 119.8 & 229.0 & 49.5 & 107.7 & 188.6 & Very fine & Very fine \\
N7 & 68.8 & 153.9 & 308.9 & 63.3 & 130.0 & 229.9 & Fine & Fine \\
N8 & 67.3 & 151.2 & 295.1 & 59.9 & 132.2 & 228.6 & Fine & Fine \\
\hline
\end{tabular}

\section{Effect of Air Pressure}

In table 5, the air pressure was none highly significant effect on the spray droplets size spectrum for the nozzles combinations N3, N4, N5, N6, N7 and N8. On the other hand, it gave the significant effect for the nozzles combinations N1 and N2. In figure 5, the effect of the air liquid pressure was significant effect on the $D_{v 0.5}$ and highly effect on the $D_{v 0.9}$. The increasing of the air pressures tends to decrease the droplet size. As well as, the statistical analysis indicated that, the interaction between the air pressures with injection angle was significant on the spray spectra. It means that the air pressure is the important factor which effect on the droplet size in the EMTF nozzles. It is also observed that the injection angle $45^{\circ}$ at $150 \mathrm{kPa}(1.5 \mathrm{bar})$ air pressure gave the highest value of the spray droplet characteristics as shown in figure 6. The spray droplet characteristics $\mathrm{D}_{\mathrm{v} 0.1}, \mathrm{D}_{\mathrm{v} 0.5}$ and $\mathrm{D}_{\mathrm{v} 0.9}$ for N1 (Lechler FT 5-608 \& TT11003) nozzle were $95.2 \mu \mathrm{m}, 226.6 \mu \mathrm{m}$ and $486.3 \mu \mathrm{m}$ at $150 \mathrm{kPa}$ air pressure respectively. As well as, the spray droplet characteristics $\mathrm{D}_{\mathrm{v} 0.1}$, $\mathrm{D}_{\mathrm{v} 0.5}$ and $\mathrm{D}_{\mathrm{v} 0.9}$ for N1 (Lechler FT 5-608 \& TT110-03) nozzle were 77.2 $\mu \mathrm{m}, 171.2 \mu \mathrm{m}$ and $206.7 \mu \mathrm{m}$ at $200 \mathrm{kPa}$ air pressure. In addition to, the spray droplet characteristics $\mathrm{D}_{\mathrm{v} 0.1}, \mathrm{D}_{\mathrm{v} 0.5}$ and $\mathrm{D}_{\mathrm{v} 0.9}$ for N5 (Lechler FT 5608 \& LU120-015) nozzle were $49.4 \mu \mathrm{m}, 112.5 \mu \mathrm{m}$ and $196.2 \mu \mathrm{m}$ at $150 \mathrm{kPa}$ air pressure respectively. As well as, the spray droplet characteristics $D_{\mathrm{v} 0.1}, D_{\mathrm{v} 0.5}$ and $\mathrm{D}_{\mathrm{v} 0.9}$ for N5 (Lechler FT 5-608 \& 
LU1120-015) nozzle were $42.8 \mu \mathrm{m}, 98 \mu \mathrm{m}$ and $184.3 \mu \mathrm{m}$ at $200 \mathrm{kPa}$ air pressure respectively .

\section{Effect of the Injection Angle}

In table 7, the injection angle was none significant effect on the spray droplet spectra for the N1, N3, N4, N5 and N6 nozzles combinations. On the other hand, it gave the significant effect for the N2, N7 and N8 nozzles combinations. The spray spectrum changed from fine to very fine by only change the injection angle from $45^{\circ}$ to $60^{\circ}$. In figure 7 , the study of the interaction of the effect of the injection angle and air pressure was significant effect only on the $\mathrm{D}_{\mathrm{v} 0.5}$ and highly effect on the $\mathrm{D}_{\mathrm{v} 0.9}$. On the other hand, it was none significant effect on the $D_{\mathrm{v} 0.1}$. The increase of injection angle tends to decrease of the droplet size spectra. As well as, the statistical analysis indicated that, as above mentioned, the interaction between the low liquid pressures with injection angle was none significant on the spray characteristic $\mathrm{D}_{\mathrm{v} 0.1}$ and $\mathrm{D}_{\mathrm{v} 0.5}$. On the other hand, it was significant effect on the $\mathrm{D}_{\mathrm{v} 0.9}$. The injection angle $45^{\circ}$ at $30 \mathrm{kPa}$ (0.3 bar) spray pressure gave the highest value of the spray droplet characteristics as shown in figure 7 . It was found that the $45^{\circ}$ at $30 \mathrm{kPa}$ ( 0.3 bar) gave a highly effect compared to the $60^{\circ}$ injection angle. The injection angle $60^{\circ}$ was produced the very fine droplets size spectrum at air pressure $200 \mathrm{kPa}$ ( 2 bar) and also $60 \mathrm{kPa}(0.6 \mathrm{bar})$. In the statistical analysis, the all interaction of the factors were highly significant effect on the $D_{v 0.9}$ and $D_{v 0.1}$ and it's were significant only on the $D_{v 0.9}$ as shown in figure 8 . The coarse and fine droplets are more preferred because they have the least chance of drift from the target area. However, smaller droplets increase the efficacy while increasing the amount of drift. Large droplets also reduce effectiveness of the application coverage but not enough to risk the occurrence of drift. Also, large droplets may rebound from the plants surface or run off (Fox et al., 1994). In this case study, the droplets from EMTF nozzles may be taken the air velocity from the air nozzle. It means also, the medium, fine and very fine droplets which produced by EMTF nozzles have the least chance of drift from the target area. We will discuss this result in the second part from this research work. 
Table 7. The interaction of the effect of the combinations of EMTF nozzles with injection angle on the droplets size spectrum.

\begin{tabular}{|c|c|c|c|c|c|c|c|c|}
\hline \multirow{3}{*}{ Nozzles } & \multicolumn{6}{|c|}{ Injection angle } & \multirow{2}{*}{\multicolumn{2}{|c|}{ Droplet Spectrum }} \\
\hline & \multicolumn{3}{|c|}{$45^{\circ}$} & \multicolumn{3}{|c|}{$60^{\circ}$} & & \\
\hline & $\mathrm{D}_{\mathrm{v} 0.1}$ & $\mathrm{D}_{\mathrm{v} 0.5}$ & $\mathrm{D}_{\mathrm{v} 0.9}$ & $\mathrm{D}_{\mathrm{v} 0.1}$ & $\mathrm{D}_{\mathrm{v} 0.5}$ & $\mathrm{D}_{\mathrm{v} 0.9}$ & $45^{\circ}$ & $60^{\circ}$ \\
\hline N1 & 85.5 & 197.8 & 539.1 & 86.8 & 199.9 & 397.6 & Fine & Fine \\
\hline $\mathrm{N} 2$ & 61.5 & 146.7 & 296.3 & 41.4 & 94.6 & 185.0 & Fine & Very fine \\
\hline N3 & 57.7 & 141.4 & 272.5 & 60.1 & 143.8 & 260.5 & Fine & Fine \\
\hline N4 & 52.4 & 114.1 & 212.2 & 51.7 & 118.9 & 242.1 & Very fine & Very fine \\
\hline N5 & 46.6 & 103.7 & 184.7 & 45.6 & 106.8 & 195.8 & Very fine & Very fine \\
\hline N6 & 51.2 & 113.9 & 212.1 & 51.1 & 113.5 & 205.5 & Very fine & Very fine \\
\hline N7 & 75.4 & 154.0 & 315.9 & 56.8 & 129.9 & 222.9 & Fine & Very fine \\
\hline N8 & 75.9 & 169.7 & 327.2 & 51.3 & 113.7 & 196.6 & Fine & Very fine \\
\hline
\end{tabular}

\section{CONCLUSION}

The results shown here demonstrate highly significant the combinations of nozzles on the droplets spectrum through to be important in the selection of the EMTF nozzles. From the results, the importance of the tongue nozzle FT5.0-608 type on the droplet is clear. The N1 EMTF nozzle produces the medium droplet size spectrum at lower spray pressure. For the same nozzles and spray pressure, the TT11003 produced the finest droplet size spectrum followed at air pressure 200 $\mathrm{kPa}(2 \mathrm{bar})$ and $60^{\circ}$ injection angle. By increasing the injection angle, it may be able to produce the finest droplet without increase the energy and costs. The low pressure application is of advantage. It reduces wear, saves energy and spares the equipment. The External mixing twin fluid nozzles EMTF may be able to reduce the water volume and application costs. In the second paper, we will investigate to test the external mixing twin fluid under wind conditions. The external mixing twin fluid may be able to reduce the drift potential.

\section{Acknowledgements}

The authors would like to acknowledge the JKI, Applied Technique Division in Braunschweig, Germany and Research Unit staff for their support and use of the wind tunnel to complete this study. Special thanks are offered to Dr. Herbst, Mr. S. Nolte, and L. Oelman in JKI and Dr. R. Heinkel from Lechler Company. 


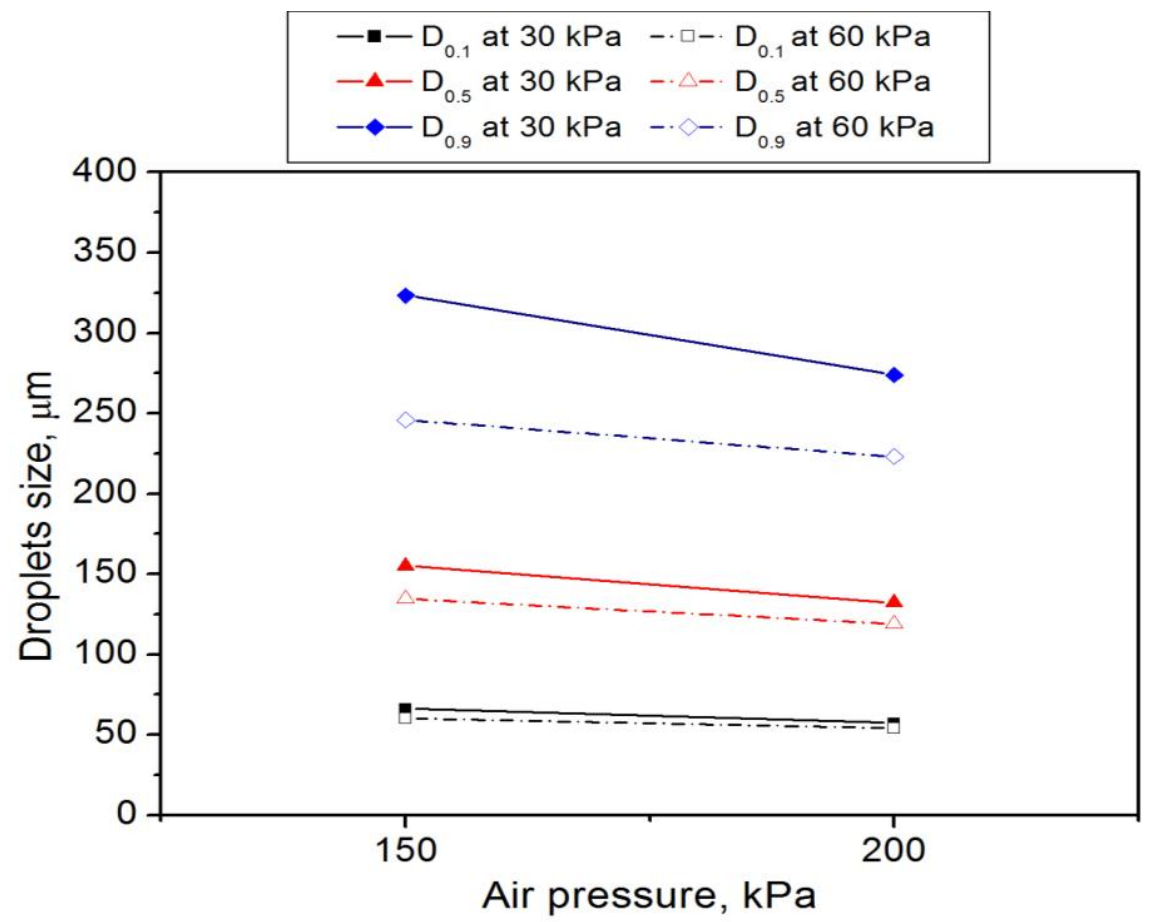

Fig. 5: External mixing twin fluid nozzle - effect of air pressure and liquid pressure on droplets size for the tongue nozzle FT5.0-608 (Lechler).

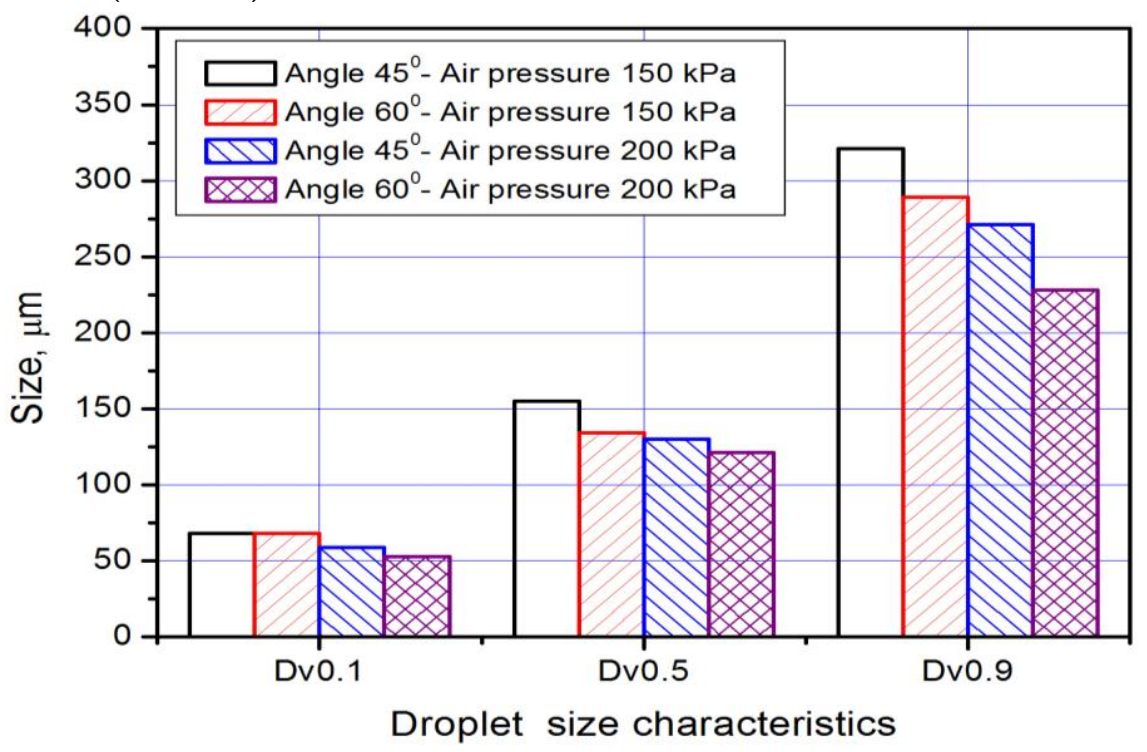

Fig. 6: Droplet size characteristics Dv0.1, Dv0.5 and Dv0.9 for different injection angles and air pressure in EMTF nozzles. 


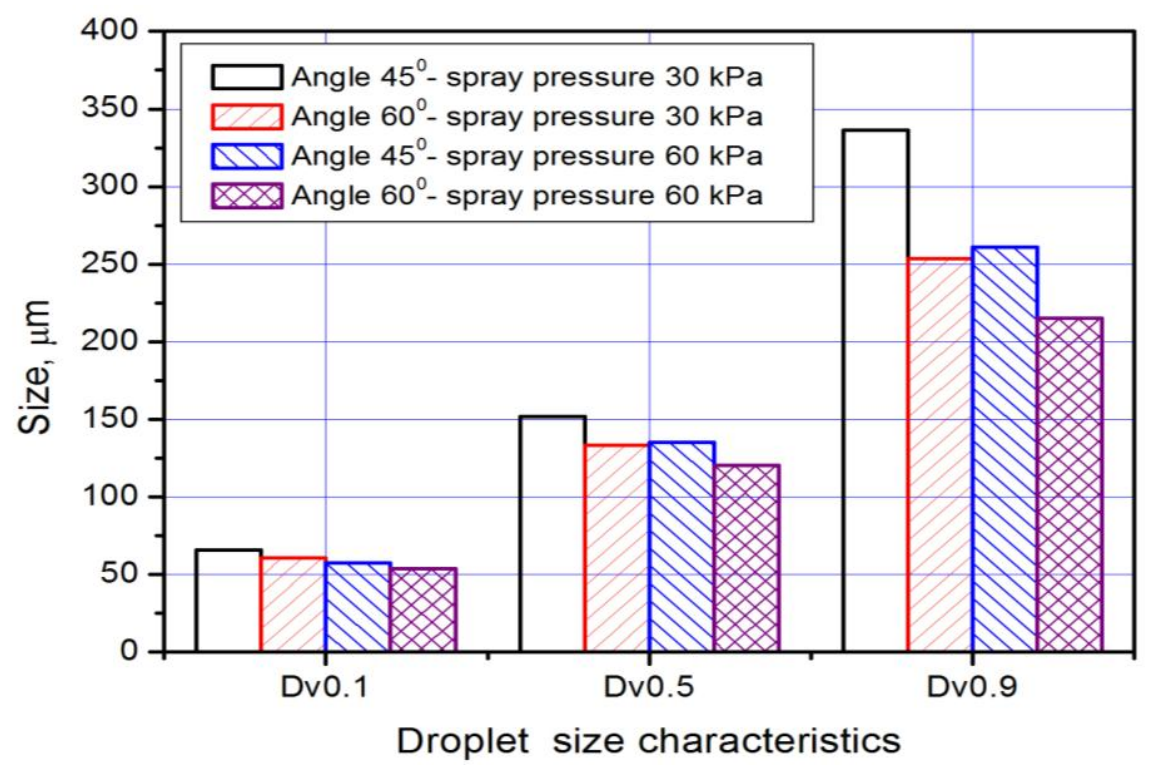

Fig. 7: Droplet size characteristics Dv0.1, Dv0.5 and Dv0.9 for different injection angles and spray pressure in EMTF nozzles.
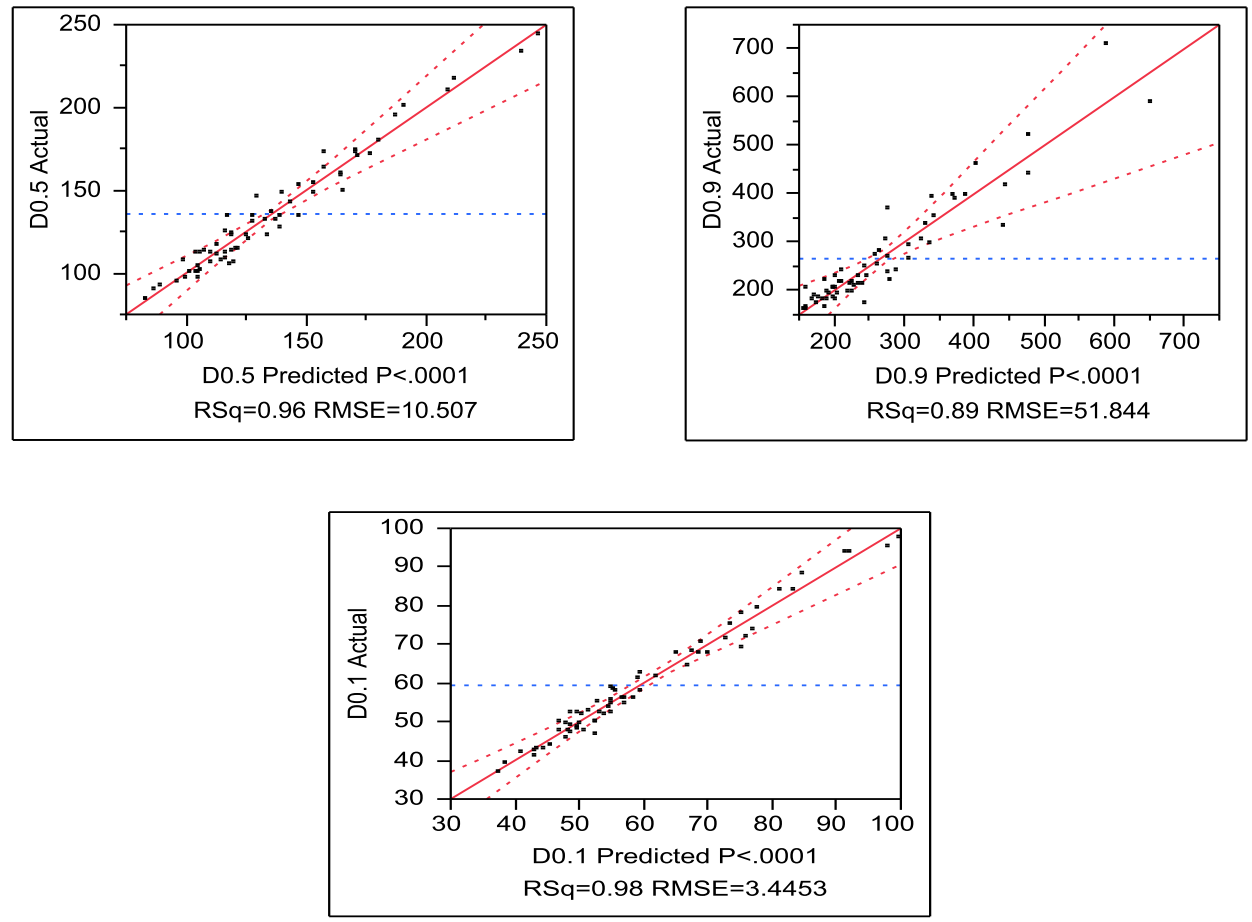

Fig. 8: Droplet size characteristics Dv0.1, Dv0.5 and Dv0.9 for all interaction effect of factors in EMTF nozzles. 


\section{REFERENCES}

ASAE Standards, 51st ed. (2003). S572. Spray nozzle classification by droplet spectra. St. Joseph, Mich.: ASAE.

Elliot J.G. and B.J. Wilson. (1983a). The Drift of Herbicides, Occasional Publication No. 2, British Crop Protection Council, Thornton Heath, U.K.

Herbst A. 2001. Droplet sizing on Agricultural sprays - A comparison of measuring systems using a standard droplet sizing classification system. Proc. ILASS - Europe Zurich, Switzerland

Hewitt, A. J. (1997). The Importance of Droplet Size in Agricultural Spraying, Atomization \& Sprays vol. 7 (3), pp. 235 - 244.

Fox, R.D., S.M. Hussein, D.L. Reichard, R.D. Brazee, and F.R. Hall (1994): A Comparison of spray drift deposited on ground and airborne spray collectors and on soybean plants. Fruit Crops 1994: A Summary of Research, OSU/OARDC Res Circular 298, 109-114.

Lefebvre A H (1989). Atomization and Sprays. Hemisphere, New York. Murphy, S.D.

Matthews G.A. 1979. Pesticide Application Methods, Longman, London and New York, $336 \mathrm{pp}$.

Nicholls T. Whybrew A. Tuck, C.R. Parkin C.S. (2001). Classification and imaging of agricultural sprays using a particle/droplet image analyser. BCPC Conference Weeds Brighton.

Pearson, S. L., T. Reed, and B. Göbel. (1993). New developments in spray tips to reduce drift. ASAE Paper No. 93-1081. St. Joseph, Mich.: ASAE.

Rutherford I; Bell G J; Freer J B S; Herrington P J; Miller P C H 1989. An evaluation of chemical application systems. Proceedings of Brighton Crop Protection Conference - Weeds, 601- 613.

Sehsah E.M.E. (2005). Application techniques for biological crop protection in Orchards and vineyards. Ph.D thesis, Hohenheim University, ISDN: 3-86186-484-3 Vorlag Grauer Stuttgart Germany. 
Sehsah E.M.E. and S. Kleisinger (2007).Effect of low pressure liquid atomizers usage in biological pest control, Misr J.Ag.Eng., 24 (1): 62-74.

Take M.E., J.W. Barry and B. Richardson. 1996. A FSCBG Sensitivity Study for Decision Support Systems, Paper No. 961037, ASAE Annual Meeting.

Tuck C R; Butler-Ellis M C; Miller P C H. 1997. Techniques for measurement of droplet size and velocity distribution in agricultural sprays. Crop Protection 16 (7), 619-628.

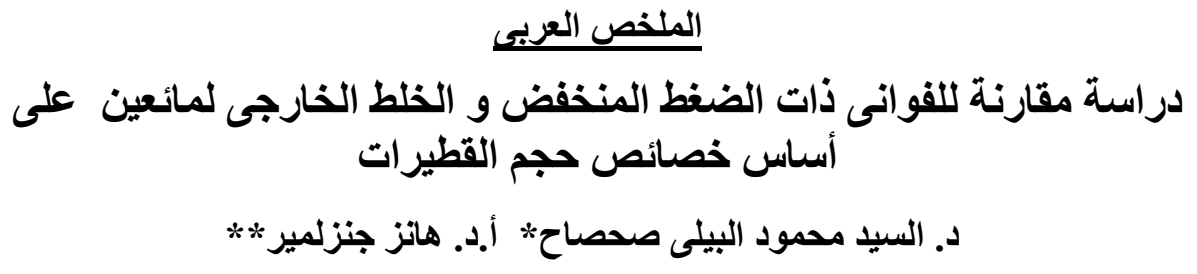

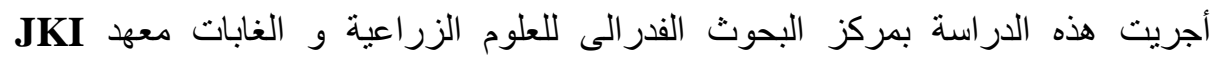
بمدينة برون شفيج بألمانيا فى ثلاثة أجزاء.

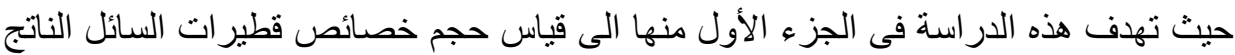

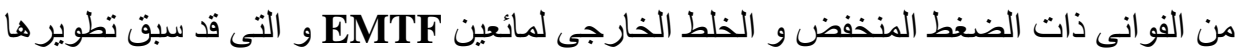

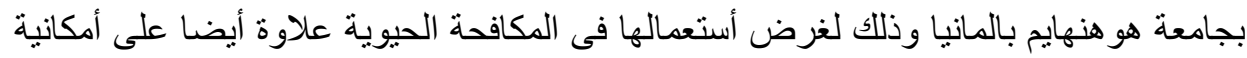

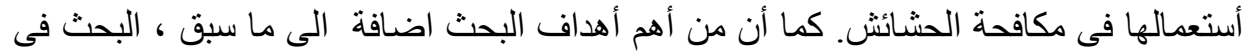

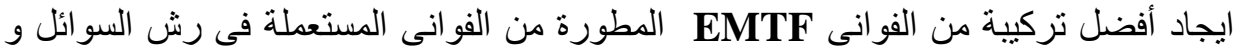

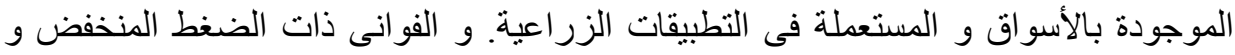

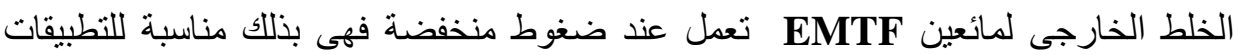
المكافحة الحيوية وهى أيضا تقلل من حجم المياه المستعملة فى الرش نظر القلة لقلة معامل تصرفها

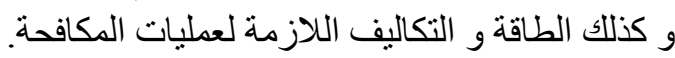

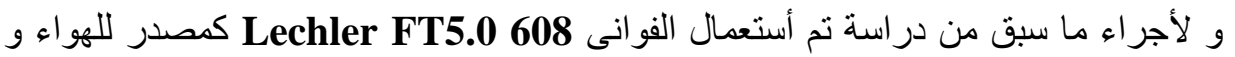

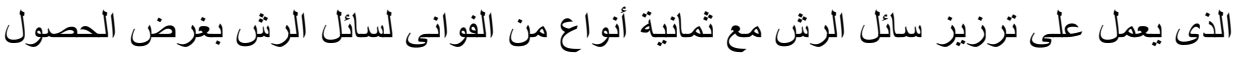

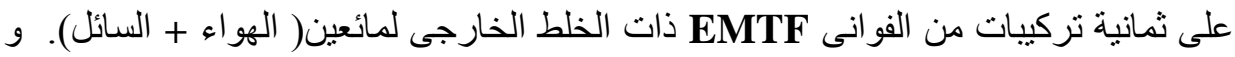

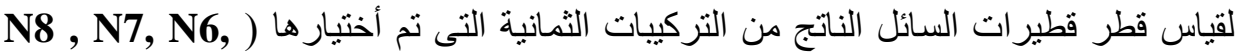
(N5, N4 N3, N2, N1

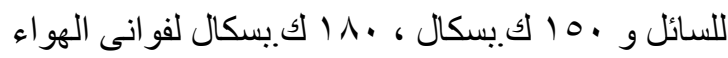

* مدرس بقسم الهندسة الزر اعبةـ كلبة الزر اعة- جامعة كفر الثيخ- مصر.

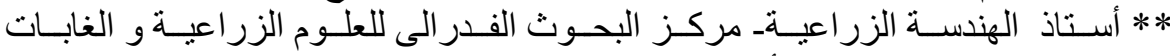
معهد) بمدينة برونشفيج بألمانيا 


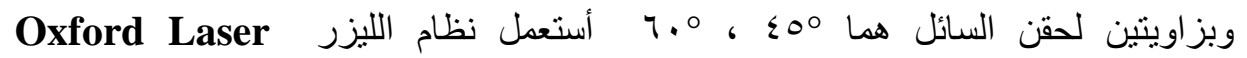

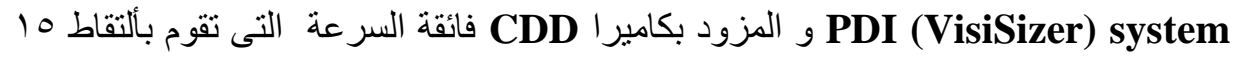

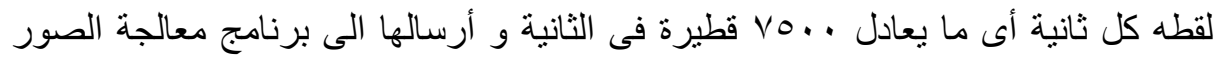
Imaging processing program

$$
\text { أهم النتائج المتحصل الحاسوب. }
$$

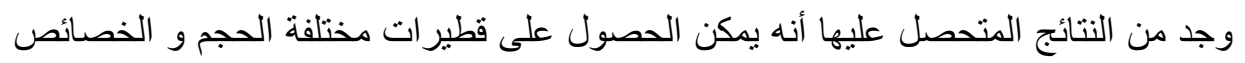

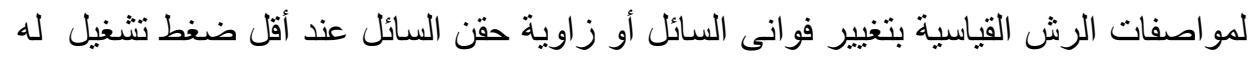

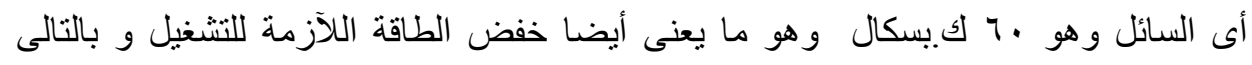

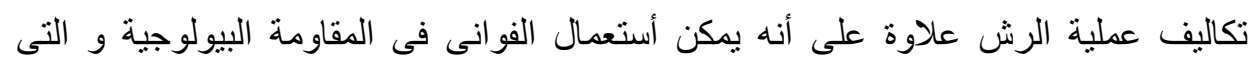

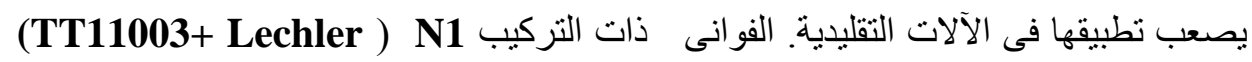
FT 5 - 608

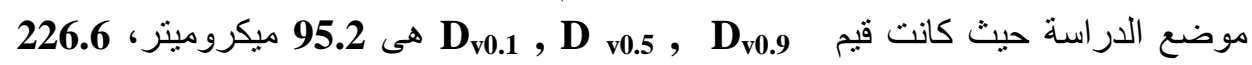

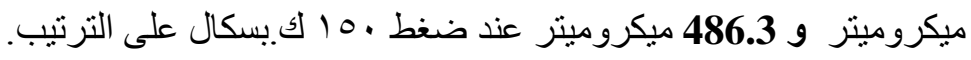
بينما كانت قيم

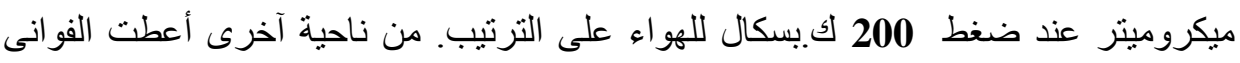

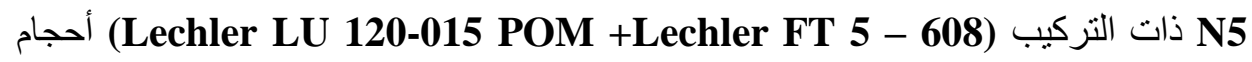
للقطير ات دقيقة جدا مقارنة بياقى الفو انى المستعملة .

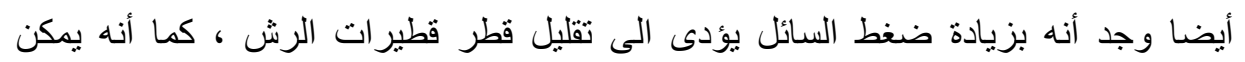

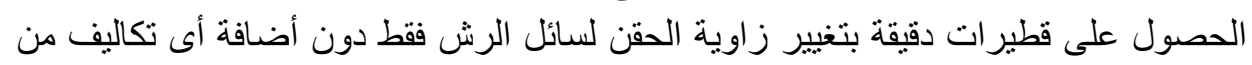

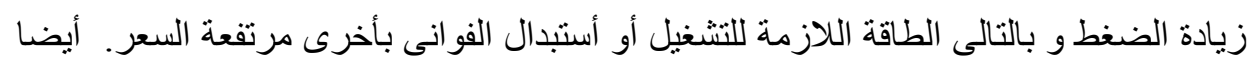

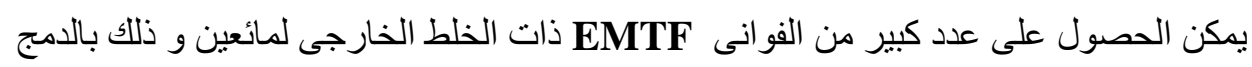

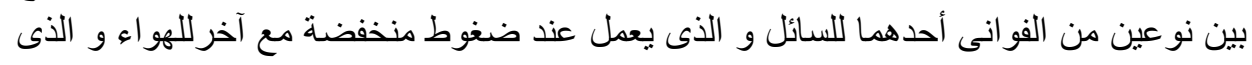

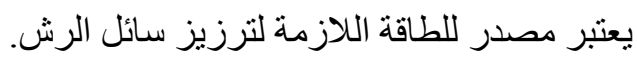


FARM MACHINERY AND POWER 